\title{
The Role of Vitamin D in Inflammatory Bowel Disease - Assessing Therapeutic and Preventive Potential of Supplementation and Food Fortification
}

\author{
Dunja Leskovar ${ }^{1 \#}$, Tomislav \\ Meštrovićc*\#, Anja Barešićc \\ Ivana Kraljevićc , Marina \\ Panek', Hana Čipčić \\ Paljetak', Mihaela Perić1, \\ Mario Matijašić , Dunja \\ Rogić ${ }^{4}$ Ana Barišićc \\ Dina Ljubas Kelečić4 \\ Darija Vranešić Bender", \\ Željko Krznarić ${ }^{4}$ and \\ Donatella Verbanac ${ }^{1,5}$ \\ 'University of Zagreb School of \\ Medicine, Šalata 3, 10000 Zagreb, \\ Croatia \\ 2Polyclinic "Dr. Zora Profozić", Bosutska \\ 19, 10000 Zagreb, Croatia \\ ${ }^{3} \mathrm{MRC}$ London Institute of Medical \\ Sciences, Du Cane Rd, London W12 \\ ONN, United Kingdom \\ ${ }^{4}$ University Hospital Centre, Kišpatićeva \\ 12, 10000 Zagreb, Croatia \\ ${ }^{5}$ University of Zagreb, Faculty of \\ Pharmacy and Biochemistry, A. \\ Kovačića 1, 10000 Zagreb, Croatia
}

Received: 16 April 2018 Accepted: 19 November 2018

\section{(1) 6}

\section{*Corresponding author:}

Phone: +38516112501;

Fax: +38516115651;

E-mail: tomislav.mestrovic@gmail.com

ORCID IDs: 0000-0002-2342-4450 (Leskovar), 0000-0002-8751-8149 (Meštrović), 0000-0002-4379-2250 (Kraljević), 0000-0003-3045-1235 (Panek), 0000-0002-1904-2193 (Perić), 0000-0001-9209-4611 (Matijašić), 0000-0001-7097-276X (Rogić), 0000-0003-1419-6967 (Barišić), 0000-0003-4310-7580 (Ljubas Kelečić), 0000-0001-7153-4753 (Vranešić Bender), 0000-0003-3758-4540 (Krznarić), 0000-0002-9106-1604 (Verbanac)

"These authors contributed equally to this work

\section{SUMMARY}

Inflammatory bowel diseases are a group of chronic inflammatory conditions that affect gastrointestinal tract due to inapt and continuous immune activation in response to a myriad of predisposing factors (most notably genetics, environmental impact and gut microbiota composition). It has been shown that vitamin D status can also play a role in the disease pathogenesis, as its deficiency is commonly observed in two major forms of inflammatory bowel diseases - Crohn's disease and ulcerative colitis. Mounting evidence supports the concept of intricate relationship between gut dysbiosis and vitamin D metabolism, while suboptimal levels of this vitamin have been linked to increased clinical disease relapse rates, inadequate response to drugs, as well as decreased quality of life in patients with Crohn's disease and ulcerative colitis. Consequently, the pertinent question is whether increased vitamin D supplementation and (on a population level) food fortification may bring significant benefit to the affected individuals. In this short review we discuss the synthesis, functions, status and food sources of vitamin D, appraise biotechnological facets of vitamin D status analysis and food fortification, and concentrate on novel developments in the field that describe its influence on intestinal microbiota and inflammatory bowel disease.

Key words: inflammatory bowel diseases, Crohn's disease, ulcerative colitis, vitamin D, gut microbiota, dysbiosis

\section{INTRODUCTION}

Vitamin D represents one of the four liposoluble vitamins in our body that has the ability to synthesise in the skin under the influence of ultraviolet (UV) radiation. It consists of two bioequivalent forms that are biologically inert and thus must be activated by undergoing a process of double hydroxylation in the liver and kidneys (1). Calcidiol (25-hydroxy-vitamin D) is an active form of vitamin D that circulates in the blood linked to globulin as a product of hydroxylation in the liver. Consequently, measuring concentrations of calcidiol is the optimal way to properly determine vitamin D status in our body. Biological half-life of calcidiol is 14 days and its normal concentration in blood is $75-150 \mathrm{nmol} / \mathrm{L}$. Concentrations less than $75 \mathrm{nmol} / \mathrm{L}$ indicate vitamin insufficiency, while its deficiency is considered when the concentrations are less than $50 \mathrm{nmol} / \mathrm{L}(2)$.

The most important role of vitamin $D$ is to regulate absorption and homeostasis of calcium. In kidneys, calcidiol converts to calcitriol (1,25-hydroxy-vitamin D) after second hydroxylation process, and this bioequivalent form increases the absorption of calcium in the small intestine, while at the same time decreases the secretion of calcium by stimulating its resorption in distal renal tubules. Furthermore, calcitriol mobilises bone minerals so hypovitaminosis leads to osteomalacia in elderly (especially women) or rickets in young children (3). Only $15 \%$ of dietary calcium and approx. $60 \%$ of phosphorus are absorbed without vitamin D; conversely, its sufficiency raises calcium and phosphorus absorption by up to 40 and $80 \%$, respectively $(4,5)$.

Production of vitamin D is influenced by UV radiation and exposure of the skin to sunlight. Therefore, skin is the main locale where its synthesis takes place. Areas above 40 degrees of south and north geographical latitude have low UV radiation, especially during winter time. 
Accordingly, people living in these areas are at greater risk of developing hypovitaminosis $\mathrm{D}$ (or vitamin $\mathrm{D}$ deficiency). Valuable source of vitamin D is food, especially fish oil (such as tuna, salmon and cod fish); however, since the intake of vitamin D with food satisfies only $20 \%$ of total daily needs, it is important to educate people on the importance of introducing foods rich in vitamin $D$ in their quotidian meal plans (6).

As a steroid hormone, vitamin D binds to nuclear receptors and regulates expression of many genes (approx. 200) that in turn facilitate various pleiotropic health benefits reported for vitamin $D(7)$. It has a wide range of effects - from insulin secretion regulation to immune system modulation - making it more similar to hormones than other vitamins $(8,9)$. Vitamin D has been implicated in a pathogenesis of various diseases such as diabetes type I, hypothyroidism, multiple sclerosis, systemic sclerosis and inflammatory bowel diseases (Crohn's disease and ulcerative colitis). Studies have also demonstrated anticancer activity of vitamin $D$, with quite a strong correlation between higher dose of calcidiol and lower incidence of colorectal carcinoma (10). Spending reasonably more time in the sun and using dietary vitamin D may prevent or even treat a plethora of malignomas (such as colorectal, breast, prostate or oesophageal cancers). Therefore, it is reasonable to expect higher usage and prescription of vitamin D supplementation in the near future (11), and there could also be a rationale for vitamin D food fortification. The aim of this review is to assess whether such approaches could be beneficial for our gut microbiota, and whether they exhibit therapeutic effects in patients affected by inflammatory bowel diseases (IBD).

\section{VITAMIN D STATUS}

Studies have generally shown insufficient concentration of vitamin $D$ in the population around the globe; it can be said that its deficiency affects $40-50 \%$ of the populace (12). There are several risk factors that contribute to this issue of epidemic proportions. As we have already mentioned earlier, sunlight exposure and UV radiation affect the synthesis of vitamin D in the skin. Due to this reason alone we can expect lower concentrations in areas with less sunlight during the year, especially in the winter and early spring period. Large meta-analysis in Saudi Arabia showed that $60 \%$ of population have deficiency of vitamin D - despite the fact this country has plenty of sunlight (13). Another risk factor is the type of skin. Darker pigmented skin contains more melanin, which acts as a natural protection from UV-B radiation. On the other hand, elderly individuals have thinner skin and lack 7-dehydrocholesterol, which is the main precursor of vitamin D (14).

Obese individuals and those with higher percentage of fat tissue are also prone to greater risk of hypovitaminosis. Nimri's (15) study on the population of female college students aged 18-26 recorded high frequency of vitamin $D$ insufficiency in overweight and obese persons. A plausible explanation should be the enhanced uptake of vitamin $D$ by adipose tissue; however, study suggests more complex and multifaceted relationship (15). Furthermore, pregnant women and women who are breast feeding for a long time are at higher risk of developing vitamin deficiency. Due to the fact that hypovitaminosis occurs in both genders, we can safely assume that external factors play a major role (16). Patients with malabsorption or other gastrointestinal (GI) diseases are at greater risk, thus preventive usage of vitamin $D$ is advised.

Europeans (including Scandinavian citizens) have the highest concentrations of vitamin D in the world (17). Different sunlight exposure, dietary intake or use of vitamin D supplements may result in such favourable landscape. However, there are some 'gaps' on this map. In the northern parts of Italy researchers have identified $51.3 \%$ postmenopausal women with vitamin D insufficiency showing seasonal variations, the highest during winter-spring season (18). Croatia as a central European country also revealed some differences. Study conducted by Laktasic-Zerjavic et al. (19) showed that $92.5 \%$ of postmenopausal women, initially screened for osteoporosis, had inadequate vitamin $D$ status. Additionally, hypovitaminosis $D$ is a major problem in Croatia affecting entire population, not only risk groups (e.g. elderly or postmenopausal women). More than $80 \%$ of healthy young males have inadequate vitamin D status, which could have significant long-term negative effects on health (20).

Generally speaking, vitamin D deficiency is more prevalent than previously thought. The Centers for Disease Control and Prevention (CDC) have shown that vitamin D sufficiency (defined by 25 -hydroxy-vitamin D of at least $30 \mathrm{ng} / \mathrm{mL}$, which is a very vague criterion) has basically halved - from $60 \%$ in Caucasian and $10 \%$ in African Americans during 1988-1994, to approx. $30 \%$ in Caucasians and $5 \%$ African Americans during 2001-2004 (21). Additionally, severe vitamin D deficiency has been demonstrated in a higher percentage of individuals (21). Moreover, even when more conservative approach to vitamin $D$ deficiency is used, a large number of patients encountered in clinical practice may be deficient in vitamin $D$ (22). Even though risk factors for vitamin D deficiency are well known, it seems that the condition has increased over time - despite fortification of food in some countries (such as USA). The condition can be aggravated by decreased sunlight exposure, decreased oral intake and/or intestinal absorption of vitamin D in patients with IBD $(6,16)$. Furthermore, one of the potential explanations is an increased awareness of this deficiency, which is why some practitioners test for vitamin $D$ deficiency even in low-risk patients (23).

Nonetheless, it has been proposed that clinicians should pursue routine testing for hypovitaminosis $D$ in patients with musculoskeletal symptoms, most notably myalgias, bone pain, and generalised weakness (22). This review aims to suggest that the same approach may be considered for patients with significant gastrointestinal symptoms as well.

\section{VITAMIN D FOOD SOURCES AND SUPPLEMENTS}

The important source of vitamin D is food (8). If there is inadequate exposure to sunlight, it is pivotal to provide additional source of vitamin $D$ to satisfy the needs of our body. 
However, since vitamin D is unstable at higher temperatures, fat-soluble and relatively complex molecule, there are certain challenges in analysing its exact concentration in food products. More specifically, this attempt necessitates food matrix digestion and concomitant extraction from fat-soluble components, extract clean-up and also a concentration step before the detection can be pursued. Analytical methods utilized to examine vitamin D in various foods include high pressure liquid chromatography (HPLC) and detection by ultraviolet absorption, mass spectrometry or a diode array detector (24). Currently used methods are all markedly similar, thus a demonstrated-performance method is used to assess their suitability (rather than defining a standard method) (24).

What we do know is that seafood, fish and eggs contain the highest concentration of vitamin D. Consequently, $100 \%$ of vitamin D total daily needs can be covered by eating $100 \mathrm{~g}$ of salmon, cod fish or mackerel (25). These species also contain significant amount of omega-3 fatty acids; however, long-living fish like tuna or salmon contain higher concentrations of mercury and other heavy metals, so the consumption should be cautiously moderate. Nowadays, fish liver oil can be found in the capsule form as one of the richest sources of vitamin $\mathrm{D}$ (25). Other nutrients containing vitamin D are milk, yogurt, egg yolks, shiitake mushrooms, cereals, oatmeal, fortified tofu, cheese, etc. Unfortunately, despite the variety of food that contains vitamin $D$, intake by food is still very poor - therefore, educating people about healthy fats and promoting Mediterranean diet can be appropriate steps towards solving this problem.

Until then, dietary supplements are often considered as a 'quick fix', and 'total vitamin D intake' always reflects the joint dietary contribution from food sources and supplements (8). Such supplements are usually available in the form of pill, tablet, capsule, or some other controlled dosage form. Vitamin D present in them can be in either vitamin D2 or vitamin D3; however, the former is rarely used as the fortificant in dietary supplements (26). The reason is that vitamin D3 shows approx. 87 $\%$ more potency for raising (and maintaining) concentrations of $25(\mathrm{OH}) \mathrm{D}$ in the serum and results in 2-3 times more storage of vitamin D than equimolar concentrations of vitamin D2 $(27,28)$.

Recommended Dietary Allowance (RDA), which is a measure that aims to reflect an average level of dietary intake per day that is deemed sufficient for meeting nutrient requirements for vitamin D in basically all healthy individuals, varies depending on the age. Thus RDA is 400 international units (IU) or $10 \mu \mathrm{g}$ in male and female infants (i.e. younger than 1 year of age), 600 IU or $15 \mu \mathrm{g}$ in all male and female individuals from 1 to 70 years of age, and $800 \mathrm{IU}$ or $20 \mu \mathrm{g}$ in those older than 70 years of age (8). It must be noted that, albeit sunlight may be considered a major source of vitamin D for certain people, RDAs of this vitamin are established on the premise of minimal sun exposure.

\section{FOOD FORTIFICATION WITH VITAMIN D}

Fortifying foods with vitamin $D$ is still not a very pervasive practice around the world. The United States and Canada have previously fortified food with vitamin D2 (29), and today in the US and European Union either vitamin D2 or vitamin D3 can be used (24). In countries where food fortification with vitamin D is permitted, foods such as margarine, milk products and breakfast cereals have become staple contributors to vitamin D intake (24). Nonetheless, there is limited data in the literature regarding technological issues of food fortification with vitamin D.

Generally, fortification can be accomplished in different ways with variable efficiency. As mentioned before, in its native form vitamin $D$ is fat soluble, although it can be prepared in water-soluble forms (e.g. emulsions) (24). Thus, adding vitamin D3 to cheese can be achieved by the addition of a commercial emulsion soluble in water, the addition of water-soluble vitamin D in multilamellar liposomes, or by the homogenisation of liposoluble crystalline vitamin $\mathrm{D}$ in a cream portion used for the standardisation of milk for cheese production (30). As only small amounts of vitamin D are necessary to meet nutrient requirements (for example, a suitable intake of vitamin D in adult women is $0.005 \mathrm{mg} /$ day in comparison to $7 \mathrm{mg} /$ day of vitamin E), low concentrations are added to foods - hence, ensuring sample homogeneity can be rather difficult (24).

Wagner et al. (31) have shown that vitamin D3 is quite stable during cheese processing and after more than one year of ripening at the temperature between 3 and $8{ }^{\circ} \mathrm{C}$. Approximately half of vitamin D3 supplemented to the milk for cheese production is subsequently bound in the whey and, thus, inaccessible for human biological processes. The added vitamin D3 is homogeneously distributed in cheese (31), and no loss is observed during fortified processed cheese manufacture or following storage for 9 months at $4-6^{\circ} \mathrm{C}$ or $21-29^{\circ} \mathrm{C}$ (32). Similar characteristics are seen for Cheddar cheese fortified with vitamin D3, where the added vitamin is stable over 9 months of storage, while consumer tests show that the fortified product is as acceptable as the unfortified one (33).

Regarding the heat stability of fortified products, heating of processed vitamin D3-fortified cheese for 3-5 min at $232^{\circ} \mathrm{C}$ results in 25-30\% vitamin loss (32). However, by applying the same conditions (i.e. heating for $5 \mathrm{~min}$ at $232^{\circ} \mathrm{C}$ ) or heating for $12 \mathrm{~min}$ at $100^{\circ} \mathrm{C}$, there is no loss of vitamin D3 observed in fortified low-fat or Cheddar cheese (31). Light can also be an issue; vitamin D3-fortified and heat-treated low-fat milk stored in clear polyethylene terephthalate (PET) containers can lose up to $66 \%$ of vitamin D3 during 12-week period; however, increasing the pigmentation level in the PET formulation may decrease that loss to $35 \%$ (34). Conversely, samples stored in the dark had a constant concentration of vitamin D3. In model systems, light-induced oxidation rate of vitamin D2 can be increased by riboflavin (35); on the other hand, by including microencapsulated lycopene in skimmed milk, riboflavin-mediated photodegradation of vitamin D3 can be decreased by $45 \%$ (36).

Taking all the aforementioned biotechnological issues into account, experience from European countries shows us that food fortification with vitamin $D$ can be a relevant strategy to address the issue of its deficiency on a population level. In Finland, vitamin $D$ fortification of fat spreads and fluid milk products in a 
systematic way started in 2003 to improve vitamin D status (37). The study that investigated the effects of such policy on vitamin D status in this population found significant improvements during the study period between 2000 and 2011 (37). In a population of Danish women with low vitamin D intake, low-dose vitamin $D$ fortification of various foods has been touted as safe and effective population-based approach by Grønborg et al. (38). Similarly, vitamin D fortification of wheat flour has been shown as a viable option for securely improving vitamin D intake and the overall status of various population groups at risk of deficiency in the United Kingdom - without increasing the risk of surpassing present reference thresholds (39).

Some researchers caution how creative food-based solutions are increasingly warranted to bridge the gap between current intake and required values of vitamin $D$, highlighting biofortification of wider range of foods (40). In short, food fortification with vitamin $D$ has been touted as a possibly optimal way to increase intake due to its widest reach and population impact.

\section{MICROBIOTA AND VITAMIN D}

Gut microbiota consists of a large number of various bacterial species that are fluctuating during human lifetime (41). Even though bacterial colonisation begins at birth, nutrition and lifestyle choices dictate its final composition. Fibre, as final product of digestion, is necessary for the production short-chain fatty acids (SCFAs) by bacteria residing in the gut. SCFAs (propionate, butyrate, or acetate) show a plethora of modulatory effects on the gastrointestinal system and metabolism (42). The connection between gut and brain is well established, and it shows that SCFAs contribute to the synthesis of many neurotrasmitters. The most representative bacteria in gut microbiota are Bacteroidetes and Firmicutes, with higher ratio of Bacteroidetes. Vegan nutrition, rich in indigestible fibre (such as inulin and galactooligosaccharides), favours the growth of Bacteroidetes; on the other hand, Western food full of refined carbohydrates and saturated fatty acids favours the growth of Firmicutes (43).

With its immunomodulatory role and the production of anti-inflammatory factors, vitamin D also exerts influence on the gut microbiota. Vitamin D receptor (VDR) is expressed on the intestinal epithelial cells, and it seems that SCFA butyrate increases its expression even more (44). Vitamin D is important for maintaining intestinal barrier integrity, thus its deficiency leads to dysbiosis and potential translocation of gut bacteria (45). The efficiency of vitamin D depends on the concentration and the ability of binding to VDR. Furthermore, the production of bile acids is increased by regular consumption of Western diet, which can adversely affect the availability of vitamin $D$ in the gut; in addition, microbial disturbances are often coupled with alterations in bile acid profiles of the host (46). More specifically, bile acids (like cholic and lithocholic acid) are ligands for VDR and, when bound to VDR, have the propensity to decrease the availability of vitamin $D$ (43). A purported strong impact of vitamin D on the gut microbiota initiated studies about possible connection between maternal vitamin D status and newborn bacterial colonisation of the intestinal tract. Maternal supplementation of vitamin D and breast feeding the infants resulted in lower burden of Clostridium difficile (47), which is a hazardous bacterial species that may give rise to pseudomembranous colitis and potentially fatal necrotizing enterocolitis in newborns.

A recent cross-sectional analysis from Brazil showed that systemic inflammation markers are highly dependent on the relationship between the composition of gut microbiota and the concentration of vitamin D (48). In this study, Prevotella species were more abundant, while Veillonella and Haemophilus species were less abundant in the subset of patients characterised by the highest vitamin D intake (48). Kanhere et al. (49) went one step further and conducted a randomized, double-blind, placebo-controlled clinical trial that aimed to assess gut and airway microbiota of patients with cystic fibrosis based on their vitamin D status. This study has shown differential gut microbiota composition in patients with vitamin D insufficiency after 12week long treatment with either vitamin D3 or placebo, with Lactococcus numbers significantly higher in the former (i.e. vitamin D3) group, and Erysipelotrichaceae and Veillonella more common in the latter (i.e. placebo) group (49). Furthermore, in an interventional pilot study, Bashir et al. (50) showed how vitamin D3 has the ability to modulate the microbiome of the upper Gl tract, with increased bacterial richness and decreased abundance of Gammaproteobacteria. All these data demonstrate that vitamin $D$ can indeed regulate the gut microbiome and that either vitamin D or VDR deficiency may result in dysbiosis, opening the door for subsequent gut injuries and an array of different diseases.

\section{INFLAMMATORY BOWEL DISEASES AND VITAMIN D}

IBD can be seen as an umbrella term for idiopathic, relapsing and remitting inflammatory diseases of gastrointestinal tract which include Crohn's disease (CD) and ulcerative colitis (UC) (51). The aetiology of IBD is multifactorial, but it is in part due to the deregulation of the immune response to various environmental factors, coupled with a pre-existing genetic predisposition (52). Both diseases commonly affect young people as a result of aberrant mucosal immune response in genetically susceptible individuals. In Croatia the incidence of UC and CD is 4.3/100 000 and 7/100 000, respectively (53). There are many risk factors affecting IBD, but smoking is the only one proved with a sort of two-faced effect, increasing the risk for $C D$ and reducing the risk for UC $(54,55)$. In CD a transmural granulomatosis inflammation can be found in any part of Gl system, although in $70 \%$ cases terminal ileum is affected. On the other hand, UC affects colonic mucosa and in a majority of cases causes proctitis (56). Both diseases manifest with episodic or chronic diarrhoea, crampy abdominal discomfort and systemic symptoms (fever, mass loss and/or malaise) (56). If there is a mixed group of abdominal symptoms without any organic cause, and all other diseases are excluded, we can diagnose irritable bowel syndrome (IBS). When the 
inflammation affects microvilli, there is a reduced ability of absorption in the intestine. Malabsorption in patients with IBD almost invariably leads to hypovitaminosis D. Large studies have shown that more than $60 \%$ of patients with IBD have inadequate concentration of vitamin $D(57)$. When compared to healthy population without IBD, the prevalence of hypovitaminosis is quite similar to patients with IBD. Also, it has been shown that solar UVB exposure reduces risk of IBD based on results from ecological studies $(58,59)$. Hence we pose the question - is it possible that hypovitaminosis D triggers IBD, or is it only a secondary result of the disease?

Plenty of different research endeavours aimed to answer that pertinent query. From an immunological perspective, vitamin $D$ regulates the immune system and calcitriol appears to play a role in the development of self-tolerance. It decreases Th1-driven autoimmune response by regulating $T$ helper cell and dendritic cell function (60). Th1 autoimmune response represents the main inflammation pathway in patients with $C D$, while Th1 cells produce proinflammatory cytokines (including IFN- $\gamma$, IL-2 and TNF-a). In vitro studies with calcitriol show the important role in reducing the production of proinflammatory cytokines and promoting $T$ helper/Th2 regulatory responses to produce anti-inflammatory interleukin (IL)-4. Patients with UC have suppressed Th2 inflammatory response in general, while evidence points to a plethora of beneficial effects on the gut immune system (Table $1 ;(61))$. Strong in vitro evidence of immunomodulatory vitamin D effects instigated human studies with vitamin D supplements in IBD, which have shown that vitamin D supplementation in IBD patients improves inflammatory bowel disease outcomes by inducing or maintaining remission, and improving quality of life scores (62).

Table 1. A summary of physiological effects of vitamin $D$ on the gut immune system according to Gubatan and Moss (61); reduced levels of vitamin D can affect all of the functions

- Protection of the integrity of the intestinal epithelial barrier

- Reduced epithelial cell injury induced by Escherichia coli or lipopolysaccharide

- Differential regulation of intestinal tight junction proteins

- Suppression of gut epithelial cell apoptosis

- Stimulation of NOD2/CAR15 expression

- Increase in antimicrobial peptides such as defensins and cathelidicin

- Proliferation control of $\mathrm{CD} 8^{+} \mathrm{T}$ cells involved in intestinal inflammation

- Inhibition of proinflammatory Th1 and Th17 cells

- Down-regulation of interleukin-23 receptor pathway

- General promotion of intestinal immune tolerance

It must be noted that clinical trials in humans that have interrogated the role of vitamin D axis in IBD are regularly heterogeneous regarding their overall design and methods used, hampering in turn the comparability of research findings ( $\mathrm{Ta}$ ble $2 ;(51-55,57,58))$. Still, most of those studies share common points of agreement on the benefits of vitamin $D$ supplementation regarding disease outcomes and achieved quality of life (63). For example, randomized trials on CD patients have shown that high doses of vitamin D3 supplementation (up to 10000 IU per day) may substantially decrease clinical relapse rates $(64,65)$, and some other studies even hinted how vitamin D supplementation (particularly in its active form) may result in short-term beneficial impact on disease activity (66). Similar results were found in patients with UC, where vitamin D supplementation (especially in high doses) resulted in diminished disease activity, better scores assessing symptom-based activity, as well as significantly improved quality of life $(67,68)$. Suboptimal levels of 25 -hydroxy-vitamin D in circulation are frequently seen in IBD and are associated with the risk of flairs, inadequate response to drugs, more common hospitalisations and surgeries, low bone mineral density, as well as deterioration of life quality (56). This is also substantiated by a very recent study where many researchers addressed vitamin $\mathrm{D}$ deficiency in a European IBD inception cohort (also known as Epi-IBD study) (69). In a total of 238 patients that were recruited between 2010 and 2011, they demonstrated high prevalence of vitamin $D$ deficiency in treatment-naive European populations with IBD, and also highlighted low vitamin D levels in patients who smoke. Such large efforts may open the door to consider food fortification with vitamin D as a viable strategy.

A shift of the composition of intestinal microbiota is probably implicated in adverse disease outcomes as well. For example, in a recent prospective controlled interventional study in Germany, Schäffler et al. (70) showed that the microbial communities found in $\mathrm{CD}$ patients were significantly altered during early vitamin $\mathrm{D}$ administration when compared to healthy controls. By analysing highly abundant species, they concluded that the vitamin D supplementation may be a harbinger of positive effects in CD - not only by modulating intestinal bacterial flora, but also by expanding the abundance of potentially beneficial bacterial species (70). Such microbial perturbations are supplemented by beneficial immune modulation that is also prompted by vitamin D supplementation; for example, it has been shown that vitamin D3 in CD patients may reduce cytokine production (most notably IL-1 $\beta$, IL- 6 and IL-10) and monocyte-derived dendritic cell maturation (71). Although the optimal protocol of vitamin D supplementation in patients with IBD is still not straightforward, recommended blood concentrations of vitamin $\mathrm{D}$ in this population are between 75 and $125 \mathrm{nmol} / \mathrm{L}$, with daily doses ranging between 1800 and $10000 \mathrm{IJ}$ (6). These values proved to be safe and beneficial in active forms of the disease.

CD and UC cannot be considered diseases of vitamin D deficiency sensu stricto; however, their pathogenesis is evidently closely related to vitamin $\mathrm{D}$ at cellular and phenotypic levels. Due to the complex relationship of vitamin D and IBD, it is extremely hard to unequivocally establish causation, and for more significant results future intervention trials should include larger cohorts of patients. For now, both theoretical and empirical support is solid enough to claim vitamin D indeed plays a substantial role in ameliorating disease parameters in patients with CD and UC (Table 2). It is thus of utmost importance to focus 
Table 2. Summary of clinical trials where vitamin D is used in the treatment of inflammatory bowel diseases (IBD) (as discussed in this review)

\begin{tabular}{|c|c|c|c|c|}
\hline Type & $N$ (patient) & Intervention & End-result & Reference \\
\hline $\begin{array}{l}\text { Randomized, double-blind, placebo-controlled } \\
\text { trial }\end{array}$ & 108 & $\begin{array}{l}1200 \text { IU of oral vitamin } \\
\text { D3 vs placebo }\end{array}$ & $\begin{array}{l}\text { Non-significant reduction of Crohn's } \\
\text { disease relapse risk }\end{array}$ & (51) \\
\hline $\begin{array}{l}\text { Randomized, double-blind, placebo-controlled } \\
\text { trial }\end{array}$ & 32 & $\begin{array}{l}10000 \text { IU D3 vs } 1000 \text { IU } \\
\text { of oral vitamin D3 }\end{array}$ & $\begin{array}{l}\text { Significant reduction of Crohn's disease } \\
\text { relapse risk only in per-protocol analysis }\end{array}$ & (52) \\
\hline Prospective clinical trial & 37 & $\begin{array}{l}\text { Active form of vitamin } D \\
\text { vs plain form of vitamin } D\end{array}$ & $\begin{array}{l}\text { Significant reduction of Crohn's disease } \\
\text { activity index and C-reactive protein }\end{array}$ & (53) \\
\hline Randomized, double-blind, prospective trial & 18 & $\begin{array}{c}2000 \text { IU vs } 4000 \text { IU of oral } \\
\text { vitamin D3 }\end{array}$ & $\begin{array}{l}\text { No significant improvement in the quality } \\
\text { of life in patients with ulcerative colitis }\end{array}$ & $(54)$ \\
\hline Prospective pilot study & 10 & $\begin{array}{c}\text { Oral liquid vitamin D } \\
\text { supplementation (5000 } \\
\text { IU in } 1 \mathrm{~mL})\end{array}$ & $\begin{array}{l}\text { Improved symptom-based IBD } \\
\text { activity scores, but no improvement } \\
\text { in objective measures of intestinal/ } \\
\text { systemic inflammation }\end{array}$ & $(55)$ \\
\hline $\begin{array}{l}\text { Prospective, longitudinal, controlled } \\
\text { interventional trial }\end{array}$ & 17 & $\begin{array}{l}380000 \mathrm{IU} \text { of vitamin } \\
\mathrm{D}(25-\mathrm{OH}) \text { in patients } \\
\text { with Crohn's disease vs } \\
\text { healthy controls }\end{array}$ & $\begin{array}{l}\text { Significant change in microbial } \\
\text { community composition in patients } \\
\text { with Crohn's disease }\end{array}$ & (57) \\
\hline $\begin{array}{l}\text { Prospective, longitudinal, placebo-controlled } \\
\text { interventional trial }\end{array}$ & 19 & $\begin{array}{l}1200 \text { IU of oral vitamin } \\
\text { D3 + calcium vs just } \\
\text { calcium }\end{array}$ & $\begin{array}{l}\text { Significantly reduced monocyte-de- } \\
\text { rived dendritic cell maturation and } \\
\text { cytokine production in patients with } \\
\text { Crohn's disease }\end{array}$ & (58) \\
\hline
\end{tabular}

on adequate vitamin $\mathrm{D}$ levels during asymptomatic periods of the disease in further interventions, while at the same time investigate potential synergistic effects with present and future treatment modalities. Regarding the latter, it should be emphasised that vitamin D3-containing nanostructured lipid carriers have already been explored as an alternative mode of treating IBD (72). Additional treatment approaches at the microbiome level represent promising opportunities towards balanced gut microbiota and improved IBD symptoms (73).

\section{CONCLUSIONS}

Vitamin D in immune-mediated disorders seems to be closely linked to bacterial composition and their metabolism, as chronic intestinal dysbiosis in compromised conditions may cause vitamin $D$ receptor dysfunction and thus trigger a vicious cycle that finally results in diseased state. A growing base of evidence supports the concept of intricate relationship between gut dysbiosis and vitamin D metabolism, which holds the potential of discovering new pathogenic mechanisms and increasing treatment options at our disposal. The research has shown how vitamin D insufficiency can be associated with gut microbiota alterations that may boost inflammation processes; therefore, impacting microbial composition with vitamin D supplementation may bring substantial benefits to the affected individuals. For now, there are still some gaps that prevent the inclusion of recommendations on manipulating vitamin D axis and gut microbiome into the guidelines for clinical practice; however, recent research is quite encouraging in instituting higher doses of vitamin D as one of the complementary approaches to our therapeutic armamentarium in IBD. In conclusion, although the answer to the question whether there is a therapeutic and preventive potential of vitamin D supplementation and food fortification in patients with CD and UC is still not straightforward, it is steadily moving towards a favourable 'yes'.

\section{FUNDING}

The authors fully acknowledge the Croatian Science Foundation (Hrvatska zaklada za znanost, HRZZ) for the support of this work under the project MINUTE for IBD (HRZZ grant no IP-11-2013-5467).

\section{CONFLICT OF INTEREST}

None.

\section{REFERENCES}

1. Borel P, Caillaud D, Cano NJ. Vitamin D bioavailability: State of the art. Crit Rev Food Sci Nutr. 2015;55(9):1193-205.

https://doi.org/10.1080/10408398.2012.688897

2. Pazirandeh S, Burns DL. Overview of vitamin D. Waltham, MA, USA: UpToDate Inc.; 2017. Available from: https://www. uptodate.com/contents/overview-of-vitamin-d.

3. Harper's illustrated biochemistry. Murray RK, Bender DA, Botham KM, Kennelly PJ, Rodwell VW, Weil PA, editors. New York, NY, USA: McGraw-Hill Medical; 2009.

4. Hilger J, Friedel A, Herr R, Rausch T, Roos F, Wahl DA, et al. A systematic review of vitamin $D$ status in populations worldwide. Br J Nutr. 2014;111(1):23-45.

https://doi.org/10.1017/S0007114513001840

5. Lappe JM, Travers-Gustafson D, Davies KM, Recker RR, Heaney RP. Vitamin D and calcium supplementation reduces cancer risk: Results of a randomized trial. Am J Clin Nutr. 2007;85(6):1586-91.

https://doi.org/10.1093/ajcn/85.6.1586

6. Vranešić Bender D, Giljević Z, Kušec V, Laktašic Žerjavić N, Bošnjak Pašic $M$, Vrdoljak $E$, et al. Guidelines for the prevention, detection and therapy of vitamin $D$ deficiency in adults. Lijec Vjesn. 2016;138(5-6):121-32. 
7. Zhang R, Li B, Gao X, Tian R, Pan Y, Jiang Y, et al. Serum 25-hydroxyvitamin $D$ and the risk of cardiovascular disease: Dose-response meta-analysis of prospective studies. Am J Clin Nutr. 2017;105(4):810-9.

https://doi.org/10.3945/ajcn.116.140392

8. Dietary reference intakes for calcium and vitamin D. Ross AC, Taylor CL, Yaktine AL, Del Valle HB, editors. Washington, DC, USA: The National Academies Press; 2011. Available from: http://www.ncbi.nlm.nih.gov/books/NBK56070/. https://doi.org/10.17226/13050

9. Ozfirat Z, Chowdhury TA. Vitamin D deficiency and type 2 diabetes. Postgrad Med J. 2010;86(1011):18-25. https://doi.org/10.1136/pgmj.2009.078626

10. Russell WR, Duncan SH, Flint HJ. The gut microbial metabolome: Modulation of cancer risk in obese individuals. Proc Nutr Soc. 2013;72(1):178-88. https://doi.org/10.1017/S0029665112002881

11. Grant WB. A review of the evidence supporting the vitamin D-cancer prevention hypothesis in 2017. Anticancer Res. 2018;38(2):1121-36.

https://doi.org/10.21873/anticanres.12331

12. Forrest KYZ, Stuhldreher WL. Prevalence and correlates of vitamin D deficiency in US adults. Nutr Res. 2011;31(1):48-54. https://doi.org/10.1016/j.nutres.2010.12.001

13. Al-Alyani H, Al-Turki HA, Al-Essa ON, Alani FM, Sadat-Ali M. Vitamin $D$ deficiency in Saudi Arabians: A reality or simply hype: A meta-analysis (2008-2015). J Family Community Med. 2018;25(1):1-4. https://doi.org/10.4103/jfcm.JFCM_73_17

14. Bruyere O, Decock C, Delhez M, Collette J, Reginster JY. Highest prevalence of vitamin $D$ inadequacy in institutionalized women compared with noninstitutionalized women: Acase-control study. Women's Health. 2009;5(1):49-54. https://doi.org/10.2217/17455057.5.1.49

15. Nimri LF. Vitamin D status of female UAE college students and associated risk factors. J Public Health. 2018;40(3):e284-90. https://doi.org/10.1093/pubmed/fdy009

16. Mithal A, Wahl DA, Bonjour JP, Burckhardt P, Dawson-Hughes B, Eisman JA, et al. Global vitamin D status and determinants of hypovitaminosis D. Osteoporos Int. 2009; 20(11):1807-20.

https://doi.org/10.1007/s00198-009-0954-6

17. Lips P. Vitamin D status and nutrition in Europe and Asia. J Steroid Biochem Mol Biol. 2007;103(3-5):620-5.

https://doi.org/10.1016/j.jsbmb.2006.12.076

18. Malavolta N, Pratelli L, Frigato M, Mulè R, Mascia ML, Gnudi $\mathrm{S}$. The relationship of vitamin $\mathrm{D}$ status to bone mineral density in an Italian population of postmenopausal women. Osteoporos Int. 2005;16(12):1691-7.

https://doi.org/10.1007/s00198-005-1883-7
19. Laktasic-Zerjavic N, Korsic M, Crncevic-Orlic Z, Kovac Z, Polasek O, Soldo-Juresa D. Vitamin D status, dependence on age, and seasonal variations in the concentration of vitamin D in Croatian postmenopausal women initially screened for osteoporosis. Clin Rheumatol. 2010;29(8):861-7. https://doi.org/10.1007/s10067-010-1409-3

20. Kastelan D, Korsic M, Kraljevicl, Dusek T, GiljevicZ, Korsic M. Low serum 25-hydroxyvitamin D concentrations in healthy young males. J Endocrinol Invest. 2009;32(6):562-3. https://doi.org/10.1007/BF03346508

21. Ginde AA, Liu MC, Camargo Jr CA. Demographic differences and trends of vitamin D insufficiency in the US population, 1988-2004. Arch Intern Med. 2009;169(6):626-32. https://doi.org/10.1001/archinternmed.2008.604

22. Kennel KA, Drake MT, Hurley DL. Vitamin D deficiency in adults: When to test and how to treat. Mayo Clin Proc. 2010; 85(8):752-7.

https://doi.org/10.4065/mcp.2010.0138

23. Basatemur E, Horsfall L, Marston L, Rait G, Sutcliffe A. Trends in the diagnosis of vitamin D deficiency. Pediatrics. 2017; 139(3):e20162748.

https://doi.org/10.1542/peds.2016-2748

24. Thomson BM, Cressey PJ. Determination of vitamin D in foods: Current knowledge and data gaps. MPI Technical Paper 2014/03. Wellington, New Zealand: Ministry for Primary Industries; 2014.

25. Lu Z, Chen TC, Zhang A, Persons KS, Kohn N, Berkowitz R, et al. An evaluation of the vitamin D3 content in fish: Is the vitamin $\mathrm{D}$ content adequate to satisfy the dietary requirement for vitamin D? J Steroid Biochem Mol Biol. 2007;103(3-5):642-4. https://doi.org/10.1016/j.jsbmb.2006.12.010

26. Rockell JEP, Skeaff CM, Venn BJ, Williams SM, Green TJ. Vitamin D insufficiency in New Zealanders during the winter is associated with higher parathyroid hormone concentrations: Implications for bone health? N Z Med J. 2008; 121(1286):75-84.

27. Heaney RP, Recker RR, Grote J, Horst RL, Armas LAG. Vitamin D3 is more potent than vitamin D2 in humans. J Clin Endocrinol Metab. 2011;96(3):E447-52.

https://doi.org/10.1210/jc.2010-2230

28. Tripkovic L, Lambert H, Hart K, Smith CP, Bucca G, Penson $S$, et al. Comparison of vitamin D2 and vitamin D3 supplementation in raising serum 25 -hydroxyvitamin $D$ status: $A$ systematic review and meta-analysis. Am J Clin Nutr. 2012; 95(6):1357-64.

https://doi.org/10.3945/ajcn.111.031070

29. Lamberg-Allardt C. Vitamin D in foods and as supplements. Prog Biophys Mol Biol. 2006;92(1):33-8. https://doi.org/10.1016/j.pbiomolbio.2006.02.017

30. Banville C, Vuillemard J, Lacroix C. Comparison of different methods for fortifying Cheddar cheese with vitamin D. Int Dairy J. 2000;10(5-6):375-82. https://doi.org/10.1016/s0958-6946(00)00054-6 
31. Wagner D, Rousseau D, Sidhom G, Pouliot M, Audet P, Vieth R. Vitamin D3 fortification, quantification, and longterm stability in Cheddar and low-fat cheeses. J Agric Food Chem. 2008;56(17):7964-9. https://doi.org/10.1021/jf801316q

32. Upreti P, Mistry VV, Warthesen JJ. Estimation and fortification of vitamin D3 in pasteurized process cheese. J Dairy Sci. 2002;85(12):3173-81. https://doi.org/10.3168/jds.s0022-0302(02)74405-6

33. Ganesan B, Brothersen C, McMahon DJ. Fortification of Cheddar cheese with vitamin D does not alter cheese flavor perception. J Dairy Sci. 2011;94(7):3708-14. https://doi.org/10.3168/jds.2010-4020

34. Saffert A, Pieper G, Jetten J. Effect of package light transmittance on the vitamin content of milk, part 3: Fortified UHT low-fat milk. Packag Technol Sci. 2009;22(1):31-7. https://doi.org/10.1002/pts.824

35. Li TL, Min DB. Stability and photochemistry of vitamin D2 in model system. J Food Sci. 1998;63(3):413-7. https://doi.org/10.1111/j.1365-2621.1998.tb15754.x

36. Montenegro MA, Nunes IL, Mercadante AZ, Borsarelli CD. Photoprotection of vitamins in skimmed milk by an aqueous doluble lycopene-gum arabic microcapsule. J Agric Food Chem. 2007;55(2):323-9. https://doi.org/10.1021/jf0622883

37. Jääskeläinen T, Itkonen ST, Lundqvist A, Erkkola M, Koskela T, Lakkala K, et al. The positive impact of general vitamin D food fortification policy on vitamin D status in a representative adult Finnish population: Evidence from an 11-y follow-up based on standardized 25-hydroxyvitamin D data. Am J Clin Nutr. 2017;105(6):1512-20.

https://doi.org/10.3945/ajcn.116.151415

38. Grønborg IM, Tetens I, Ege M, Christensen T, Andersen EW, Andersen R. Modelling of adequate and safe vitamin D intake in Danish women using different fortification and supplementation scenarios to inform fortification policies. Eur J Nutr. 2018;in press. https://doi.org/10.1007/s00394-017-1586-9

39. Allen RE, Dangour AD, Tedstone AE, Chalabi Z. Does fortification of staple foods improve vitamin $D$ intakes and status of groups at risk of deficiency? A United Kingdom modeling study. Am J Clin Nutr. 2015;102(2):338-44.

https://doi.org/10.3945/ajcn.115.107409

40. Cashman KD. Vitamin D: Dietary requirements and food fortification as a means of helping achieve adequate vitamin D status. J Steroid Biochem Mol Biol. 2015;148:19-26. https://doi.org/10.1016/j.jsbmb.2015.01.023

41. Lozupone CA, Stombaugh Jl, Gordon Jl, Jansson JK, Knight R. Diversity, stability and resilience of the human gut microbiota. Nature. 2012;489(7415):220-30.

https://doi.org/10.1038/nature11550
42. Campbell Y, Fantacone ML, Gombart AF. Regulation of antimicrobial peptide gene expression by nutrients and by-products of microbial metabolism. Eur J Nutr. 2012;51(8): 899-907.

https://doi.org/10.1007/s00394-012-0415-4

43. Riccio $P$, Rossano R. Diet, gut microbiota, and vitamins $D+A$ in multiple sclerosis. Neurotherapeutics. 2018;15(1):75-91. https://doi.org/10.1007/s13311-017-0581-4

44. Sun J.VDR/vitamin D receptor regulates autophagic activity through ATG16L1. Autophagy. 2016;12(6):1057-8.

https://doi.org/10.1080/15548627.2015.1072670

45. Zhao H, Zhang H, Wu H, Li H, Liu L, Guo J, et al. Protective role of $1,25(\mathrm{OH})_{2}$ vitamin $\mathrm{D}_{3}$ in the mucosal injury and epithelial barrier disruption in DSS-induced acute colitis in mice. BMC Gastroenterol. 2012;12:57.

https://doi.org/10.1186/1471-230X-12-57

46. Joyce SA, Gahan CGM. Disease-associated changes in bile acid profiles and links to altered gut microbiota. Dig Dis. 2017;35(3):169-77.

https://doi.org/10.1159/000450907

47. Talsness CE, Penders J, Jansen EHJM, Damoiseaux J, Thijs C, Mommers M. Influence of vitamin D on key bacterial taxa in infant microbiota in the KOALA Birth Cohort Study. PLoS ONE. 2017;12(11):e0188011.

https://doi.org/10.1371/journal.pone.0188011

48. Luthold RV, Fernandes GR, Franco-de-Moraes AC, Folchetti LGD, Ferreira SRG. Gut microbiota interactions with the immunomodulatory role of vitamin $\mathrm{D}$ in normal individuals. Metab Clin Exp. 2017;69:76-86.

https://doi.org/10.1016/j.metabol.2017.01.007

49. Kanhere M, He J, Chassaing B, ZieglerTR, Alvarez JA, Ivie EA, et al. Bolus weekly vitamin D3 supplementation impacts gut and airway microbiota in adults with cystic fibrosis: A double-blind, randomized, placebo-controlled clinical trial. J Clin Endocrinol Metab. 2018;103(2):564-74.

https://doi.org/10.1210/jc.2017-01983

50. Bashir M, Prietl B, Tauschmann M, Mautner SI, Kump PK, Treiber $\mathrm{G}$, et al. Effects of high doses of vitamin D3 on mucosa-associated gut microbiome vary between regions of the human gastrointestinal tract. Eur J Nutr. 2016;55(4):1479-89. https://doi.org/10.1007/s00394-015-0966-2

51. Van der Sloot KWJ, Amini M, Peters V, Dijkstra G, Alizadeh BZ. Inflammatory bowel diseases: Review of known environmental protective and risk factors involved. Inflamm Bowel Dis. 2017;23(9):1499-509. https://doi.org/10.1097/MIB.0000000000001217

52. Mudambi K, Bass D. Vitamin D: Abrief overview of its importance and role in inflammatory bowel disease. Translational Gastroenterol Hepatol. 2018;3:31.

https://doi.org/10.21037/tgh.2018.05.03

53. Vucelić B, Čuković-Čavka S. Inflammatory bowel diseases. Medicus. 2006;15(1):53-62. 
54. Peng Y, Liu X, Wang X. Environmental risk factors for induction of the inflammatory bowel disease. Zhong Nan Da Xue Xue Bao Yi Xue Ban. 2017;42(9):1100-4 (in Chinese). https://doi.org/10.11817/j.issn.1672-7347.2017.09.017

55. Cosnes J, Beaugerie L, Carbonnel F, Gendre JP. Smoking cessation and the course of Crohn's disease: An intervention study. Gastroenterology. 2001;120(5):1093-9. https://doi.org/10.1053/gast.2001.23231

56. Sairenji T, Collins KL, Evans DV. An update on inflammatory bowel disease. Prim Care. 2017;44(4):673-92. https://doi.org/10.1016/j.pop.2017.07.010

57. Mouli VP, Ananthakrishnan AN. Review article: Vitamin D and inflammatory bowel diseases. Aliment Pharmacol Ther. 2014;39(2):125-36. https://doi.org/10.1111/apt.12553

58. Fioletov VE, McArthur LJB, Mathews TW, Marrett L. Estimated ultraviolet exposure levels for a sufficient vitamin D status in North America. J Photochem Photobiol B. 2010; 100(2):57-66. https://doi.org/10.1016/j.jphotobiol.2010.05.002

59. Sonnenberg A, Genta RM. Geographic distributions of microscopic colitis and inflammatory bowel disease in the United States. Inflamm Bowel Dis. 2012;18(12):2288-93. https://doi.org/10.1002/ibd.22932

60. Cantorna MT, Mahon BD. Mounting evidence for vitamin D as an environmental factor affecting autoimmune disease prevalence. Exp Biol Med. 2004;229(11):1136-42. https://doi.org/10.1177/153537020422901108

61. Gubatan J, Moss AC. Vitamin D in inflammatory bowel disease: More than just a supplement. Curr Opin Gastroenterol. 2018;34(4):217-225.

https://doi.org/10.1097/MOG.0000000000000449

62. Reich KM, Fedorak RN, Madsen K, Kroeker KI. Vitamin D improves inflammatory bowel disease outcomes: Basic science and clinical review. World J Gastroenterol. 2014; 20(17):4934-47.

https://doi.org/10.3748/wjg.v20.i17.4934

63. Del Pinto R, Ferri C, Cominelli F. Vitamin D axis in inflammatory bowel diseases: Role, current uses and future perspectives. Int J Mol Sci. 2017;18(11):2360.

https://doi.org/10.3390/ijms18112360

64. Jørgensen SP, Agnholt J, Glerup H, Lyhne S, Villadsen GE, Hvas CL, et al. Clinical trial: Vitamin D3 treatment in Crohn's disease $-\mathrm{A}$ randomized double-blind placebo-controlled study. Aliment Pharmacol Ther. 2010;32(3):377-83. https://doi.org/10.1111/j.1365-2036.2010.04355.x
65. Narula N, Cooray M, Anglin R, Muqtadir Z, Narula A, Marshall JK. Impact of high-dose vitamin D3 supplementation in patients with Crohn's disease in remission: A pilot randomized double-blind controlled study. Dig Dis Sci. 2017;62(2):448-55. https://doi.org/10.1007/s10620-016-4396-7

66. Miheller P, Müzes G, Hritz I, Lakatos G, Pregun I, Lakatos PL, et al. Comparison of the effects of 1,25 dihydroxyvitamin $\mathrm{D}$ and 25 hydroxyvitamin $\mathrm{D}$ on bone pathology and disease activity in Crohn's disease patients. Inflamm Bowel Dis. 2009;15(11):1656-62. https://doi.org/10.1002/ibd.20947

67. Mathur J, Naing S, Mills P, Limsui D. A randomized clinical trial of vitamin D3 (cholecalciferol) in ulcerative colitis patients with hypovitaminosis D3. PeerJ. 2017;5:e3654.

https://doi.org/10.7717/peerj.3654

68. Garg M, Rosella O, Rosella G, Wu Y, Lubel JS, Gibson PR. Evaluation of a 12-week targeted vitamin D supplementation regimen in patients with active inflammatory bowel disease. Clin Nutr. 2018;37(4):1375-82.

https://doi.org/10.1016/j.clnu.2017.06.011

69. Chetcuti Zammit S, Ellul P, Girardin G, Valpiani D, Nielsen KR, Olsen J, et al. Vitamin D deficiency in a European inflammatory bowel disease inception cohort: An Epi-IBD study. Eur J Gastroenterol Hepatol. 2018;30(11):1297-303. https://doi.org/10.1097/meg.0000000000001238

70. Schäffler H, Herlemann DP, Klinitzke P, Berlin P, Kreikemeyer B, Jaster R, Lamprecht G. Vitamin D administration leads to a shift of the intestinal bacterial composition in Crohn's disease patients, but not in healthy controls. J Dig Dis. 2018; 19(4):225-34.

https://doi.org/10.1111/1751-2980.12591

71. Bartels LE, Bendix M, Hvas CL, Jørgensen SP, Agnholt J, Agger $\mathrm{R}$, Dahlerup JF. Oral vitamin D3 supplementation reduces monocyte-derived dendritic cell maturation and cytokine production in Crohn's disease patients. Inflammopharmacology. 2014;22(2):95-103.

https://doi.org/10.1007/s10787-013-0197-1

72. Zai K, Hirota M, Yamada T, Ishihara N, Mori T, Kishimura A, et al. Therapeutic effect of vitamin D3-containing nanostructured lipid carriers on inflammatory bowel disease. J Control Release. 2018;286:94-102. https://doi.org/10.1016/j.jconrel.2018.07.019

73. Matijašić $M$, Meštrović $T$, Perić $M$, Čipčić Paljetak $H$, Panek $M$, Vranešić Bender D,et al. Modulating composition and metabolic activity of the gut microbiota in IBD patients. Int J Mol Sci. 2016;17(4):578.

https://doi.org/10.3390/ijms17040578 